TITLE:

\title{
Orientation control of poly(vinylidenefluoride- trifluoroethylene) crystals and molecules using atomic force microscopy
}

\section{$\operatorname{AUTHOR}(\mathrm{S})$ :}

Kimura, K; Kobayashi, K; Yamada, H; Horiuchi, T; Ishida, K; Matsushige, $\mathrm{K}$

\section{CITATION:}

Kimura, K ... [et al]. Orientation control of poly(vinylidenefluoride-trifluoroethylene) crystals and molecules using atomic force microscopy. APPLIED PHYSICS LETTERS 2003, 82(23): 4050-4052

\section{ISSUE DATE:}

2003-06-09

URL:

http://hdl.handle.net/2433/39655

\section{RIGHT:}

Copyright 2003 American Institute of Physics. This article may be downloaded for personal use only. Any other use requires prior permission of the author and the American Institute of Physics. 


\title{
Orientation control of poly(vinylidenefluoride-trifluoroethylene) crystals and molecules using atomic force microscopy
}

\author{
Kuniko Kimuraa) \\ Matsushige Laboratory, Department of Electronic Science and Engineering, Kyoto University, \\ Kyoto 606-8501, Japan and Innovative Cluster Creation Project, Kyoto University, Kyoto 606-8501, Japan \\ Kei Kobayashi \\ International Innovation Center, Kyoto University, Kyoto 606-8501, Japan \\ Hirofumi Yamada, Toshihisa Horiuchi, Kenji Ishida, and Kazumi Matsushige ${ }^{\text {b) }}$ \\ Department of Electronic Science and Engineering, Kyoto University, Kyoto 606-8501, Japan
}

(Received 14 January 2003; accepted 8 April 2003)

\begin{abstract}
We have developed an aligning technique for polymer crystals and molecular chains utilizing contact-mode atomic force microscopy (AFM). We have aligned lamellar crystals and molecular chains of poly(vinylidenefluoride-trifluoroethylene) thin films. By scanning the film surface using an AFM cantilever tip at the temperature range of $70-100^{\circ} \mathrm{C}$, we aligned the crystals to the scan direction. Moreover, we successfully aligned the molecular chains to the scan direction by scanning at a higher temperature $\left(135^{\circ} \mathrm{C}\right)$. The aligned chains subsequently formed large lamellar crystals, which were still ferroelectric. (C) 2003 American Institute of Physics. [DOI: 10.1063/1.1581974]
\end{abstract}

Orientation control of crystals or molecules in polymer films is essential for the introduction of anisotropy in their material properties such as elastic constant, sound velocity, refractive index, and dielectric constant. In particular, orientation control in local regions is greatly useful for the development of nanometer-scale structures in polymer materials. The stretching method, one of the most common orientation control techniques for thick polymer films, is not suitable for control in specific localized areas. Recently, orientation control of liquid crystals using atomic force microscopy (AFM) has been demonstrated. ${ }^{1-4}$ In this technique, a thin polymer film was rubbed by an AFM tip for aligning liquid crystals on its surface. The driving forces of liquid-crystal alignment are rubbed grooves ${ }^{1}$ or some structural changes on the polymer surface which were imaged by friction microscopy. ${ }^{2}$ However, the orientation of polymer molecules is not elucidated yet.

We have developed a technique to align small crystals or molecules to the desired direction using an AFM cantilever tip with precise control of film temperature and applied load. In this letter, we describe how we applied this technique to vinylidenefluoride and trifluoroethylene copolymer (P(VDFTrFE)) thin films. The copolymer has a strong intrinsic polarization originating from $\mathrm{C}-\mathrm{F}$ dipoles and shows remarkable ferroelectric properties ${ }^{5,6}$ at the temperature lower than the Curie point $\left(T_{C}\right)$. Many studies on the ferroelectric properties of this material, ${ }^{7}$ including piezoelectricity ${ }^{8}$ and its application to high-frequency $(>100 \mathrm{MHz})$ ultrasonic transducers, ${ }^{9}$ have been reported. Recently, the structural and ferroelectric properties of this copolymer at nanometer scale have been studied using AFM. ${ }^{10-12}$

$\mathrm{P}(\mathrm{VDF}-\mathrm{TrFE})$ thin films used in this study were prepared as follows. A methylethylketon solution of P(VDF-

\footnotetext{
${ }^{a)}$ Electronic mail: kimurak@iic.kyoto-u.ac.jp

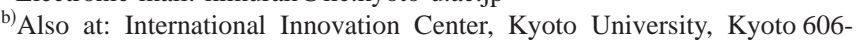
8501, Japan.
}

TrFE)(75/25 molar content) was spin coated on a graphite substrate. The sample was annealed at $140{ }^{\circ} \mathrm{C}$ for $1 \mathrm{~h}$ to improve crystallinity. The surfaces of the films prepared by the same procedure were imaged by electron microscopy as randomly oriented rectangular or ellipsoidal crystals. ${ }^{13,14}$ They are lamellar crystals whose lamellar planes are perpendicular to the film surface and the molecular chains in the lamella are aligned perpendicular to the longer axes of the crystals with folding turns. ${ }^{13}$ We believe that the structure of our films is the same as that in the previous studies. The 25-nm-thick and 75-nm-thick copolymer films, obtained as described, herein, were used for the experiments. The film thickness was measured from the line profile of AFM images across a pin hole. We used a commercially available AFM instrument (JEOL JSPM4200) equipped with a heating stage. We used a Si cantilever (Nanosensors CONT) with a nominal spring constant of $0.2 \mathrm{~N} / \mathrm{m}$ and a tip radius of about 10 $\mathrm{nm}$. For the experiments of electrical poling and piezoelectric response imaging described later, the same cantilever was used with its tip side coated with 30-nm-thick Rh. All experiments were done in an ambient condition.

In order to modify the microscopic orientation of the film, an AFM tip in contact with the film surface was scanned in the direction perpendicular to the longer axis of the cantilever (we refer to this process as "modification scan") with a scanning line spacing of $8 \mathrm{~nm}$, an applied load of $2 \mathrm{nN}$, and a tip velocity of $20 \mu \mathrm{m} / \mathrm{s}$. The film surface was kept at $80^{\circ} \mathrm{C}$ during the modification scan but imaged at $30^{\circ} \mathrm{C}$ in the contact mode using the same cantilever. Figure 1(a) shows a topographic image after the modification. The lower half corresponds to the region where the modification scan was performed. We can clearly see in Fig. 1(a) that the longer axes of lamellar crystals are well aligned in the scan direction. The result indicates that lamellar crystals are rotated by the AFM tip, and that their longer axes are aligned in the scan direction as illustrated in Fig. 1(b). The degree of 


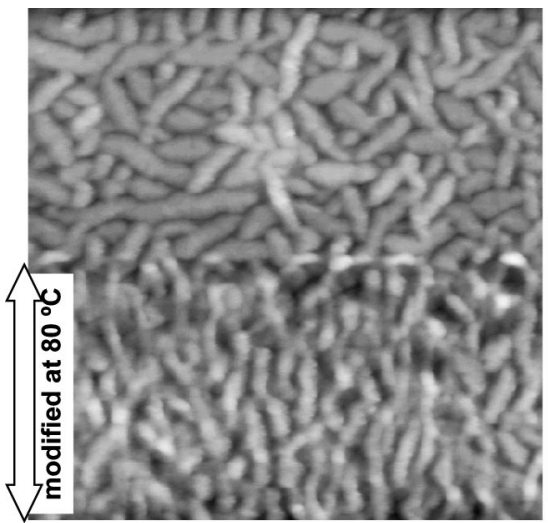

(a)

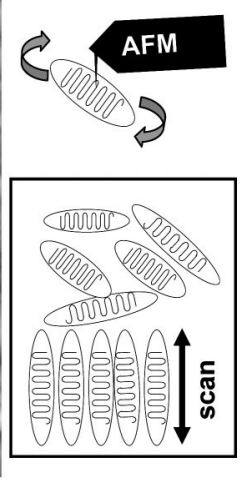

(b)
FIG. 1. (a) Topographic image of a 25-nm-thick $\mathrm{P}(\mathrm{VDF}-\mathrm{TrFE})$ film $(2 \mu \mathrm{m} \times 2 \mu \mathrm{m})$. Lower half was modified at $80^{\circ} \mathrm{C}$ by scanning an AFM tip along an arrow. (b) Schematic illustrations of the aligning technique for lamellar crystals and its result.

the crystal alignment deteriorated when the modification scan was done at $50^{\circ} \mathrm{C}$. It suggests that the amorphous region existing around the crystals should be sufficiently soft for the smooth movement of the crystals.

We consider the molecular chains can be affected during the modification process near the melting point $\left(T_{m}\right), 147^{\circ} \mathrm{C}$ in this copolymer, ${ }^{8}$ because of their large thermal fluctuation. In fact, the modification scan right below $T_{m}$ drastically changed the result. We scanned $2 \mu \mathrm{m} \times 2 \mu \mathrm{m}$ area of a 75nm-thick $\mathrm{P}(\mathrm{VDF}-\mathrm{TrFE})$ film at $135^{\circ} \mathrm{C}$ using the same cantilever with a load of $3 \mathrm{nN}$ and a tip velocity of $4 \mu \mathrm{m} / \mathrm{s}$. Figure 2(a) shows a topographic image taken at $30^{\circ} \mathrm{C}$ after the modification scan. The lower three quarters in Fig. 2(a) correspond to the region modified at $135^{\circ} \mathrm{C}$ by the scanning in the direction indicated by an arrow. The longer axes of the lamellar crystals were perfectly aligned in the direction perpendicular to the scan. A possible explanation for this result is that the tip scan at this temperature directly arranged the molecular chains rather than the crystals, as schematically illustrated in Fig. 2(b), and that molecules subsequently formed lamellar crystals whose longer axes were perpendicular to the scan direction. In fact, this structure is very similar to that of the stretched thick P(VDF-TrFE) films. ${ }^{13}$

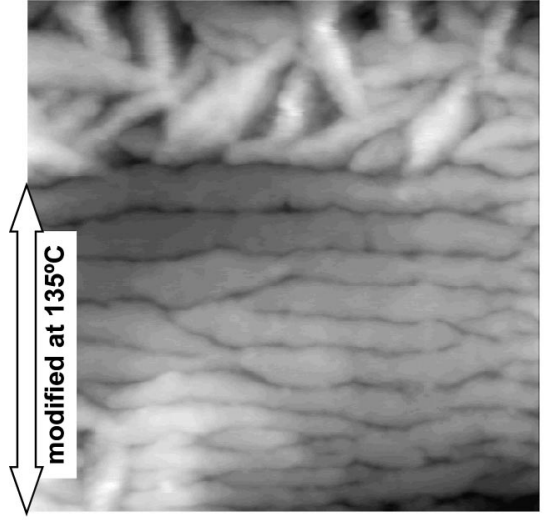

(a)

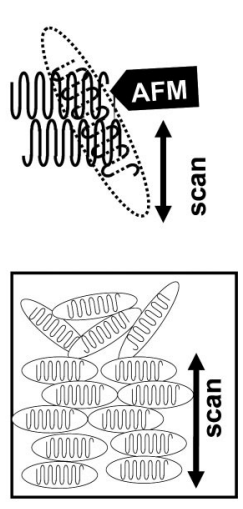

(b)
FIG. 2. (a) Topographic image of a 75-nm-thick $\mathrm{P}(\mathrm{VDF}-\mathrm{TrFE})$ film $(1 \mu \mathrm{m} \times 1 \mu \mathrm{m})$. Lower three quarters were modified at $135^{\circ} \mathrm{C}$ by scanning an AFM tip along an arrow. (b) Schematic illustrations of the aligning tech-

nique for molecular chains and its result.
Downloaded 30 May 2007 to 130.54.110.22. Redistribution subject to AIP license or copyright, see http://apl.aip.org/apl/copyright.jsp

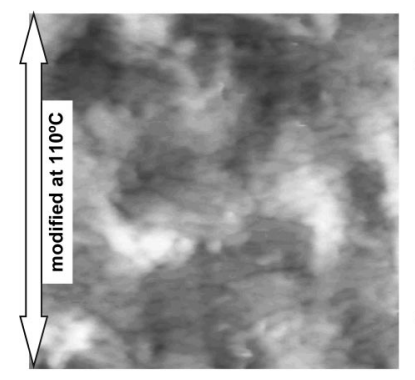

(a)

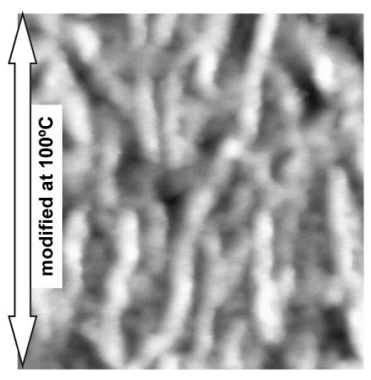

(b)
FIG. 3. Topographic images of 75 -nm-thick P(VDF-TrFE) films $(1 \mu \mathrm{m}$ $\times 1 \mu \mathrm{m}$ ): (a) modified at $110^{\circ} \mathrm{C}$ and (b) modified at $100{ }^{\circ} \mathrm{C}$ by scanning an AFM tip along arrows.

This result strongly depended on the temperature of modification scan. When we scanned at $130^{\circ} \mathrm{C}$, a similar structure to the one in Fig. 2(a) was obtained. However, the size of lamellar crystals was heavily reduced after the modification scan at lower temperature. Figure 3(a), imaged at $30^{\circ} \mathrm{C}$, shows a topographic image of a 75-nm-thick P(VDFTrFE) film which was modified at $110^{\circ} \mathrm{C}$. The lamellar crystals drastically shrank compared to the ones in Fig. 2(a), but their longer axes were still perpendicular to the modification scan. Furthermore, when the modification temperature was reduced to $100^{\circ} \mathrm{C}$, the lamellar crystals were aligned not perpendicular but parallel to the scan direction as shown in Fig. 3(b), that is due to the same phenomenon as seen in Fig. 1 (a).

We consider the mechanism of orientation control of molecular chains as follows. The molecular conformation changes at $T_{C}$ from all-trans to the statistical combination of isomers constructed by all-trans, trans-gauche, and trans-gauche ${ }^{\prime} ., 15$ The molecular chains of this copolymer are rather rigid in the ferroelectric phase, whereas $\mathrm{C}-\mathrm{C}$ main chains are rotationally fluctuated around their axes above $T_{C}\left[\left(\sim 123^{\circ} \mathrm{C}\right)\right.$ Ref. 8$] .{ }^{16}$ In addition, the molecular chains in the paraelectric phase are considered very soft in the chain direction from its elastic modulus. ${ }^{13}$ These facts support the possible alignment of the molecular chains with an AFM tip above $T_{C}$. The measurements of differential scanning calorimetry for $\mathrm{P}(\mathrm{VDF}-\mathrm{TrFE})$ (74/26) (Ref. 8) suggest that some parts of the crystals change to the paraelectric phase above $105^{\circ} \mathrm{C}$, which explains well the results shown in Figs. 3(a) and 3(b).

We performed polarization reversal and piezoelectric response imaging on the crystals modified at $135^{\circ} \mathrm{C}$ to obtain certain proof of their ferroelectricity. First, a certain area of a 75-nm-thick P(VDF-TrFE) film was scanned at $135^{\circ} \mathrm{C}$, using the conductive cantilever tip in the same modification condition as before. Then, we poled a $1 \mu \mathrm{m} \times 1 \mu \mathrm{m}$ area, which is inside the modified area, by scanning the tip with a dc voltage of $-7 \mathrm{~V}$ at $30^{\circ} \mathrm{C}$, and made another $0.3 \mu \mathrm{m}$ $\times 0.3 \mu \mathrm{m}$ polarized area with the opposite polarity in the previously poled area by applying $+7 \mathrm{~V}$. The polarization of this area was visualized by piezoelectric response imaging using the same tip with an applied ac bias voltage $(10 \mathrm{kHz}$, $\left.1 \mathrm{~V}_{p p}\right)$. The amplitude-and-phase signal $(A \cos \phi)$ of the cantilever deflection induced by the piezoelectric vibration of the film was detected by a lock-in amplifier. ${ }^{17}$ Figures 4 (a) and 4(b) show a topographic image and a piezoelectric re- 


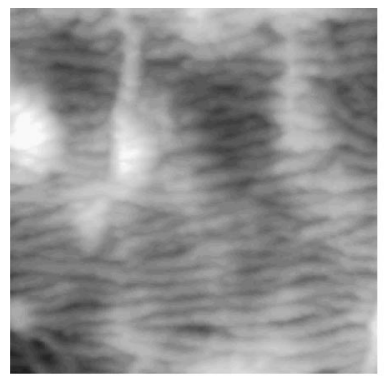

(a)

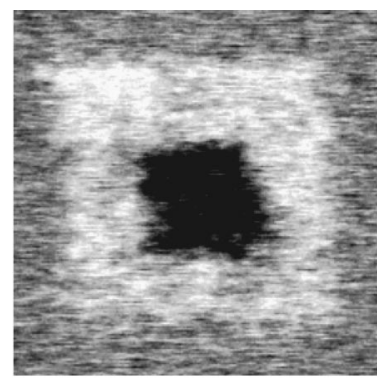

(b)
FIG. 4. (a) Topographic image and (b) piezoelectric response image of a 75-nm-thick $\mathrm{P}(\mathrm{VDF}-\mathrm{TrFE})$ film $(1.5 \mu \mathrm{m} \times 1.5 \mu \mathrm{m})$. After modification at $135^{\circ} \mathrm{C}$, the film was poled with $-7 \mathrm{~V}(1 \mu \mathrm{m} \times 1 \mu \mathrm{m})$, and poled again with $+7 \mathrm{~V}(0.3 \mu \mathrm{m} \times 0.3 \mu \mathrm{m})$ in the previously poled area.

sponse image of the poled area measured at $30^{\circ} \mathrm{C}$, respectively. We have confirmed that the crystals in the area where molecular chains were aligned at $135^{\circ} \mathrm{C}$ were polarized and their polarization was reversible. These results show that the lamellar crystals artificially formed at $135^{\circ} \mathrm{C}$ are ferroelectric.

In summary, the lamellar crystals and molecular chains of $\mathrm{P}(\mathrm{VDF}-\mathrm{TrFE})$ thin films were aligned by the AFM scan in appropriate conditions. The modification scan above $T_{C}$ made the molecular chains of $\mathrm{P}(\mathrm{VDF}-\mathrm{TrFE})$ remarkably well aligned. We believe that our technique is applicable to other many crystalline polymers by heating at the temperature close to their $T_{m}$.

The authors would like to thank Professor Masamichi Hikosaka, Professor Hideki Miyaji, and Professor Hiroji
Ohigashi for useful discussions about the crystal structure of $\mathrm{P}(\mathrm{VDF}-\mathrm{TrFE})$, and Daikin Industries Ltd. for providing $\mathrm{P}(\mathrm{VDF}-\mathrm{TrFE})$. This work was supported by an Innovative Cluster Creation Project and a Grant-in-Aid for Scientific Research from the Ministry of Education, Culture, Sport, Science, and Technology of Japan.

${ }^{1}$ M. Rüetschi, P. Grütter, J. Fünfschilling, and H.-J. Güntherodt, Science (Washington, DC, U.S.) 265, 512 (1994).

${ }^{2}$ A. J. Pidduck, S. D. Haslam, G. P. Bryan-Brown, R. Bannister, and I. D. Kitely, Appl. Phys. Lett. 71, 2907 (1997).

${ }^{3}$ B. Wen, M. P. Mahajan, and C. Rosenblatt, Appl. Phys. Lett. 76, 1240 (2000).

${ }^{4}$ J.-H. Kim, M. Yoneya, and J. Yamamoto, Appl. Phys. Lett. 78, 3055 (2001).

${ }^{5}$ T. Furukawa, M. Date, and E. Fukada, Jpn. J. Appl. Phys., Part 2 19, L109 (1980).

${ }^{6}$ K. Kimura and H. Ohigashi, Appl. Phys. Lett. 43, 834 (1983).

${ }^{7}$ K. Tashiro and M. Kobayashi, Phase Transitions 18, 213 (1989).

${ }^{8}$ H. Ohigashi and K. Koga, Jpn. J. Appl. Phys., Part 2 21, L455 (1982).

${ }^{9}$ K. Kimura and H. Ohigashi, J. Appl. Phys. 61, 4749 (1987).

${ }^{10}$ X. Chen, H. Yamada, T. Horiuchi, and K. Matsushige, Jpn. J. Appl. Phys., Part 1 38, 3932 (1999).

${ }^{11}$ L. M. Blinov, R. Barberi, S. P. Palto, M. P. De Santo, and S. G. Yudin, J. Appl. Phys. 89, 3960 (2001).

${ }^{12}$ T. Fukuma, K. Kobayashi, T. Horiuchi, H. Yamada, and K. Matsushige, Thin Solid Films 397, 133 (2001).

${ }^{13}$ H. Ohigashi, S. Akama, and K. Koga, Jpn. J. Appl. Phys., Part 1 27, 2144 (1988).

${ }^{14}$ K. Kimura and H. Ohigashi, Jpn. J. Appl. Phys., Part 1 25, 383 (1986).

${ }^{15}$ A. J. Lovinger, T. Furukawa, G. T. Davis, and M. G. Broadhurst, Polymer 24, 1233 (1983).

${ }^{16}$ K. Tashiro, K. Takano, M. Kobayashi, Y. Chatani, and H. Tadokoro, Polymer 25, 195 (1984).

${ }^{17}$ P. Güthner and K. Dransfeld, Appl. Phys. Lett. 61, 1137 (1992). 